\title{
PinX1-siRNA/mPEG-PEI-SPION combined with doxorubicin enhances the inhibition of glioma growth
}

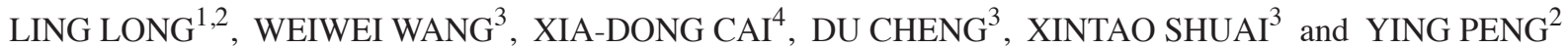 \\ ${ }^{1}$ Department of Neurology, The Third Affiliated Hospital, Sun Yat-Sen University, Guangzhou, Guangdong 510630; \\ ${ }^{2}$ Department of Neurology, Sun Yat-Sen Memorial Hospital, Sun Yat-Sen University, Guangzhou, Guangdong 510120; \\ ${ }^{3}$ Center of Biomedical Engineering, School of Chemistry and Chemical Engineering, Sun Yat-Sen University, Guangzhou, \\ Guangdong 510275; ${ }^{4}$ Department of Neurology, The Sixth Affiliated Hospital (Guangdong Gastrointestinal and \\ Anal Hospital), Sun Yat-Sen University, Guangzhou, Guangdong 510655, P.R. China
}

Received October 17, 2013; Accepted February 19, 2014

DOI: $10.3892 /$ etm.2014.1586

\begin{abstract}
Resistance to chemotherapy and the side effects of anticancer drugs are the major obstacles for glioma treatment. The aim of the present study was to develop a novel approach for the treatment of gliomas that improved the therapeutic effect; the anticancer drug, doxorubicin (DOX), was combined with short interfering (si)RNA and monomethoxy polyethylene glycol polyethylenimine superparamagnetic iron oxide nanoparticle (mPEG-PEI-SPION), a magnetic resonance imaging (MRI)-visible nanoparticle. Specific siRNA molecules, delivered by mPEG-PEI-SPION, were employed to knockdown the PIN2-interacting protein 1 (PinX1) gene in C6 glioma cells. PinX1 is a nucleolar protein associated with telomere and telomerase. C6 cells were treated with DOX and/or PinX1-siRNA. The results of the transfection experiments revealed that siRNA/mPEG-PEI-SPION was transfected into C6 cells with high efficiency. PinX1-siRNA was unable to inhibit C6 cells, while in the PinX1-siRNA + DOX group, the same dose of DOX caused an increased loss of cell viability. Therefore, mPEG-PEI-SPION was shown to be viable for siRNA delivery into C6 cells and coadministration of DOX with PinX1-siRNA may be a potential therapeutic method for inhibiting gliomas.
\end{abstract}

\section{Introduction}

Gliomas are the most common primary malignant tumor of the adult central nervous system, accounting for $\sim 40 \%$ of

Correspondence to: Professor Ying Peng, Department of Neurology, Sun Yat-Sen Memorial Hospital, Sun Yat-Sen University, 107 West Yanjiang Road, Guangzhou, Guangdong 510120, P.R. China

E-mail:2353352460@qq.com

Key words: monomethoxy polyethylene glycol polyethyleneimine superparamagnetic iron oxide nanoparticle, doxorubicin, PIN2-interacting protein 1, short interfering RNA, glioma intracranial tumors (1). Gliomas have the worst prognosis due to chemoresistance and radioresistance. Despite multimodality treatments with extensive surgical resection, radiotherapy or chemotherapy, the median survival time of glioma patients is $\sim 1$ year $(2,3)$. Therefore, novel strategies are urgently required to increase the survival rate of glioma patients.

The C6 cell line is a rat glioma cell line that is induced by $\mathrm{N}$-nitrosomethylurea. This cell line is widely adopted for glioma study due to the histocompatibility in various categories of rats and the infiltrative growth pattern that is similar to human glioma (4). Therefore, C6 cells were employed in the present study as the cell model for glioma.

Doxorubicin (DOX) is an anticancer agent with a wide spectrum, including breast cancer, lung cancer, leukemia, lymphoma and glioma (5). DOX can penetrate through the cell membrane into cells and combine with chromosomes. The antitumor effects of DOX are exerted mainly through forming a complex with double stranded DNA and strongly interfering with the synthesis of DNA, RNA and also proteins (6). A previous study demonstrated that DOX is able to insert into DNA and cause the splitting of DNA by topoisomerase II. An additional antitumor mechanism of DOX is associated with redox (7). A series of NADPH-dependent cytoreductases reoxidize DOX into semiquinone radicals, which react with oxygen to produce cytotoxic chemicals, including peroxides, hydroxide radicals and hydrogen peroxides. In addition, DOX is hypothesized to combine with lipids on the cell membrane, interfering with a number of cell functions. DOX yields antitumor effects through one or more of the aforementioned mechanisms and cells in all stages of the cell cycle are sensitive to DOX, particularly those in hyperplastic tissues, including tumors. Despite this, the application of DOX is limited due to the side effects, including gastrointestinal adverse reactions, alopecia, allergy, myelosuppression and heart toxicity, among which dose-dependent heart failure is the most significant (8). In addition, specific resistance may occur more easily in single drug therapy. These factors hinder the clinical utility of DOX. However, one method of reducing the side effects and resistance is to use the drug in conjunction with other agents.

Telomeres are nucleoprotein complexes composed of $(\mathrm{TTAGGG})^{\mathrm{n}}$ repeats and a specialized protein complex that 
protect the chromosome-ends from being recognized as deleterious DNA double-stranded breaks, which activates DNA damage responses (9). Telomere length is maintained by telomerase, a specialized reverse transcriptase, that adds TTAGGG repeats to the ends of the chromosomes. In humans and other long-living mammals, telomerase expression is repressed in the majority of somatic cells. As a result, telomeres become increasingly shorter with continuous cell divisions due to the 'end-replication' problem (10). This progressive telomere shortening functions as a cell-autonomous barrier against overproliferation, making a potent tumor-suppressor mechanism. The re-expression of telomerase is a key event in tumorigenesis, which is supported by the evidence that telomerase is present in $90 \%$ of human cancers (11). The role of telomerase in glioma has also been established, with the rat glioma C6 cell line included. Therefore, telomerase is hypothesized to be a novel and effective target for the therapy of gliomas $(12,13)$.

With fast development of molecular biology and genetics, numerous genes have been identified that are closely associated with tumorigenesis, including a number of oncogenes and tumor suppressor genes. PIN2-interacting protein 1 (PinX1), a nucleolar protein associated with telomere/telomerase, is a putative tumor suppressor. However, the role of $\mathrm{PinX1}$ in telomerase/telomere regulation and cancer remains unclear (14). The expression of the PinX1 mRNA transcript is present in the majority of tested human tumors (15-17). Certain studies consider PinX1 to be an intrinsic telomerase/telomere inhibitor and a putative tumor suppressor, as it binds to and suppresses telomerase enzymatic activity (18). However, other experiments have demonstrated that the depletion of PinX1 expression shortens telomere length and inhibits proliferation in yeast cells (19). In addition, Zhang et al demonstrated that silencing PinX1 induces senescence in telomerase-positive cancer cells (20). Therefore, in the present study, PinX1-short interfering (si)RNA was used to downregulate PinX1 mRNA expression and subsequently study the effect on telomerase.

siRNA is rapidly becoming an important tool for gene knockdown and the analysis of gene function (21). Knockdown of specific pathogenic genes is a potent approach for treating diseases, including tumors. In the present study, PinX1 was knocked-down in C6 cells and cell viability was analyzed to confirm the potential of PinX1 as a target gene for the treatment of gliomas. Furthermore, gliomas were treated with a combination of PinX1-siRNA and DOX, with the aim of increasing the efficiency of the treatment and decreasing the side effects.

A major challenge in the study of siRNA is the development of an appropriate delivery system with high efficiency and low toxicity. In previous years, nonviral vectors have become attractive options, among which nanoparticles are suitable candidates for the siRNA delivery system (22). Nanoparticles are a series of structures in the nanometer scale size range $(\leq 100 \mathrm{~nm})$ that retain unique properties. Nanoparticles include polymeric micelles, dendrimers, polymeric and ceramic nanoparticles, protein cage architectures, viral-derived capsid nanoparticles, polyplexes and liposomes (23). As siRNA carriers, nanoparticles have overwhelming superiority since they are biocompatible and biodegradable with strong penetrability and good capacity, but have low toxicity and immunogenecity. Furthermore, by functionalizing the surface with synthetic polymers and appropriate ligands, nanoparticles can be targeted to specific cells and locations within the body or be endowed with specific properties. Superparamagnetic iron oxide nanoparticle (SPION), a highly efficient T2 contrast agent for magnetic resonance imaging (MRI), is widely used experimentally for agent delivery (24). The aforementioned attributes of the SPION-based carrier system enable broad biomedical applications, particularly in in vivo studies. In the present study, siRNA molecules with SPION-labeled nanoparticles were delivered to C6 cells to confirm the suitability of this method as a transfection tool. The results of the study may be the foundation for future animal model experiments.

\section{Materials and methods}

Materials and reagents. Monomethoxy polyethylene glycol [mPEG; molecular weight cut off (MWCO), $2 \mathrm{kDa}$ ] and $\mathrm{N}, \mathrm{N}^{\prime}$-carbonyldiimidazole (CDI) were purchased from Sigma-Aldrich (St. Louis, MO, USA). Hyperbranched polyethyleneimine (PEI; MWCO, $25 \mathrm{kDa}$ ) was purchased from BASF (Ludwigshafen, Rheinland-Pfalz, Germany). Tetrahydrofuran and chloroform $\left(\mathrm{CHCl}_{3}\right)$ were dried over calcium hydride and distilled prior to use. SPIONs, with an average diameter of $6 \mathrm{~nm}$, were synthesized according to the method reported by Sun et al (25). Glioma C6 cells were obtained from the American Type Culture Collection (Rockville, MD, USA) and cell culture media and fetal bovine serum (FBS) were purchased from Invitrogen Life Technologies (Carlsbad, CA, USA). Double-stranded oligonucleotides with homology to a desired target region of PinX1 were synthesized by Guangzhou RiboBio Co., Ltd. (Guangzhou, China) and the target sequence was GCTGTGGATCCCAGAAATA. Cy3-control siRNA and negative control (NC) siRNA were also supplied by Guangzhou RiboBio Co., Ltd. DOX was obtained from Shenzhen Wanle Pharmaceutical Co., Ltd. (Shenzhen, China). Total RNA was extracted with the TRIzol reagent (Invitrogen, Carlsbad, CA, USA). A SYBR PrimeScript quantitative polymerase chain reaction (qPCR) kit and primers were supplied by Takara Biotechnology, Co., Ltd. (Dalian, China). A bicinchoninic acid (BCA) kit was purchased from Pierce Biotechnology, Inc. (Rockford, IL, USA) and a TeloTAGGG Telomerase PCR ELISA kit was purchased from Roche Diagnostics Corporation (Indianapolis, IN, USA). Cell Counting Kit-8 (CCK-8) was obtained from Dojindo (Kumamoto, Japan) and the Hoechst 33243 stain was purchased from Sigma-Aldrich.

Synthesis of mPEG-PEI-SPION. The mPEG-PEI complex was prepared as previously described (26). The hydroxyl terminal groups of $\mathrm{mPEG}$ were activated by CDI in order to allow the conjugation of mPEG to branched PEI. Next, CDI-activated mPEG was conjugated to PEI. The mPEG-PEI-SPION complex was prepared by a 'ligand exchange' method as previously reported (27). In total, $200 \mathrm{mg} \mathrm{mPEG}-\mathrm{PEI}$ and $10 \mathrm{mg}$ SPION were dissolved in $2 \mathrm{ml} \mathrm{CHCl}_{3}$. The solution was stirred overnight at room temperature and then precipitated with hexane. The precipitate was dispersed into double distilled water under sonication. Large aggregates 
were removed by filtering through a $220 \mathrm{~nm}$ membrane. The encapsulation efficiency of the SPION was determined using a polarized Zeeman Atomic Absorption Spectrophotometer (Z-2000 series).

Polyplex siRNA/mPEG-PEI-SPION formation. siRNA and an appropriate amount of mPEG-PEI-SPION (100 nmol siRNA:3.53 $\mu \mathrm{g}$ mPEG-PEI-SPION) $(\mathrm{N} / \mathrm{P}=5)$ were dissolved separately in double distilled water. The two solutions were mixed by gentle pipetting and the mixture was maintained at room temperature for $30 \mathrm{~min}$ to allow polyplex formation.

$\zeta$-potential and size measurements. The $\zeta$-potential measurements of mPEG-PEI-SPION and siRNA/mPEG-PEI-SPION were conducted using a ZetaPlus instrument (Brookhaven Instruments Corporation, Holtsville, NY, USA) at an angle of $15^{\circ}$ at $25^{\circ} \mathrm{C}$. The average values plus the SDs were based on the data of three runs. Nanoparticle size was determined using the same instrument at $25^{\circ} \mathrm{C}$. Scattering light was detected at a $90^{\circ}$ angle and the sizes determined were the mean values of three runs plus the SD.

Cell culture. The rat glioma C6 cell line was maintained in high glucose Dulbecco's modified Eagle's medium, supplemented with $10 \%$ FBS and penicillin/streptomycin, at $37^{\circ} \mathrm{C}$ in a fully humidified atmosphere of $5 \% \mathrm{CO}_{2}$. When the cells reached confluence, they were trypsinized and subcultured.

Transfection efficiency of siRNA/mPEG-PEI-SPION. C6 glioma cells were plated in 24-well plates $\left(5 \times 10^{4}\right.$ cells/well) and allowed to grow overnight. Cy3-siRNA and $\mathrm{mPEG}-\mathrm{PEI}-\mathrm{SPION}$ (at $\mathrm{N} / \mathrm{P}=5$ ) were mixed by gentle pipetting and then incubated for $30 \mathrm{~min}$ at room temperature. The original cell culture medium was replaced with medium containing the complexes (concentration of siRNA was $100 \mathrm{nM}$ ). The culture was incubated for $4 \mathrm{~h}$ at $37^{\circ} \mathrm{C}$. After $4 \mathrm{~h}$, the medium was discarded and the cells were washed twice with phosphate-buffered saline (PBS). Next, cells were fixed with paraformaldehyde for $30 \mathrm{~min}$. After washing twice, the cells were stained with $10 \mu \mathrm{g} / \mathrm{ml}$ Hoechst 33243 for $15 \mathrm{~min}$. The cells were observed under a fluorescence microscope (Carl Zeiss AG, Jena, Germany) and fluorescent images were captured and recorded.

$q P C R$. C6 cells were plated in 12 -well plates $\left(1 \times 10^{5}\right.$ cells/well $)$ and allowed to grow overnight. Next, the cells were transfected with $100 \mathrm{nM}$ NC-siRNA/mPEG-PEI-SPION or $100 \mathrm{nM}$ PinX1-siRNA/mPEG-PEI-SPION complexes (at $\mathrm{N} / \mathrm{P}=5$ ) as aforementioned. Cells were washed with pre-chilled PBS and collected in TRIzol reagent $48 \mathrm{~h}$ following transfection. Total RNA was extracted with the TRIzol reagent according to the instructions provided by the manufacturer. First strand cDNA was synthesized from $1 \mu \mathrm{g}$ total RNA. The reaction conditions were as follows: $37^{\circ} \mathrm{C}$ for $15 \mathrm{~min}$ and $85^{\circ} \mathrm{C}$ for $5 \mathrm{sec}$. PCR was performed in a $20 \mu 1$ volume ( $1 \mu \mathrm{l}$ cDNA) with SYBR green dye. Sequence-specific oligonucleotide primers were as follows: PinX1, 5'-AACCACCTGGGACTTGGAGCTA-3' (forward) and 5'-CCTGACCATGGCAAGTGTTGA-3' (reverse); and $\beta$-actin, 5'-GGAGATTACTGCCCTGGCTCCTA-3' (forward) and 5'-GACTCATCGTACTCCTGCTTGCTG-3' (reverse). The reaction conditions were as follows: $95^{\circ} \mathrm{C}$ for $30 \mathrm{sec}$, followed by 40 cycles of $95^{\circ} \mathrm{C}$ for $5 \mathrm{sec}$ and $60^{\circ} \mathrm{C}$ for 34 sec. $\beta$-actin was amplified as the housekeeping gene and qPCR assays of all the samples were performed in triplicate.

Telomerase activity assay. Telomerase activity was measured with a TeloTAGGG Telomerase PCR ELISA kit. C6 cells were transfected with NC-siRNA/mPEG-PEI-SPION or PinX1-siRNA/mPEG-PEI-SPION as aforementioned. After $48 \mathrm{~h}$, cellular extracts were prepared with 1X CHAPS lysis buffer. The protein concentration was determined using a BCA kit. An extract equal to $1 \mu \mathrm{g}$ protein was amplified with the reaction mixture included in the kit. The extract and reaction mixture were maintained at $25^{\circ} \mathrm{C}$ for $30 \mathrm{~min}$, then heated at $90^{\circ} \mathrm{C}$ for 3 min and subjected to 30 cycles of PCR with specific programing $\left(94^{\circ} \mathrm{C}\right.$ for $30 \mathrm{sec}, 50^{\circ} \mathrm{C}$ for $30 \mathrm{sec}$ and $72^{\circ} \mathrm{C}$ for $90 \mathrm{sec}$ ). Following an additional $10 \mathrm{~min}$ at $72^{\circ} \mathrm{C}$, the amplification products were subjected to hybridization and ELISA, according to the instructions provided by the manufacturer. The absorbance value of each sample was calculated using a microplate reader at $450 \mathrm{~nm}$, with a reference of $690 \mathrm{~nm}$. Each sample was tested in triplicate.

Cell viability. For the CCK-8 test, C6 cells were plated in 96-well plates at an initial density of $1 \times 10^{4}$ cells/well. PinX1-siRNA/mPEG-PEI-SPION and NC-siRNA/mPEG-PEI-SPION (at N/P=5) complexes were constructed as aforementioned. The original cell culture medium was replaced with medium containing one of the complexes (100 nM siRNA) and the cells were incubated for $4 \mathrm{~h}$ at $37^{\circ} \mathrm{C}$. After $4 \mathrm{~h}$, the medium was replaced with fresh complete medium, with or without $10 \mu \mathrm{g} / \mathrm{ml} \mathrm{DOX}$, and cells were allowed to grow for $20 \mathrm{~h}$. After $24 \mathrm{~h}$ of DOX incubation, the CCK- 8 reagent was added to the wells and incubated at $37^{\circ} \mathrm{C}$ for $1 \mathrm{~h}$. Absorbance at $570 \mathrm{~nm}$ of each well was recorded with the microplate reader. Each treatment group was replicated in three wells.

Cell apoptosis. C6 cells were plated in 24-well plates (5x $10^{4}$ cells/well) and allowed to grow overnight. Transfection and DOX incubation were performed as aforementioned. Following DOX incubation for $24 \mathrm{~h}$, the medium was discarded and the cells were washed with PBS three times. Next, cells were fixed with paraformaldehyde for $30 \mathrm{~min}$ and washed twice. The cells were stained with $10 \mu \mathrm{g} / \mathrm{ml}$ Hoechst 33243 for $15 \mathrm{~min}$ and a fluorescence microscope was used for observation.

Statistical analysis. Results were analyzed using SPSS version 12.0 (SPSS, Inc., Chicago, IL, USA) and compared using one way analysis of variance with Fisher's least significant difference post hoc test. Data are presented as the mean \pm SD and $\mathrm{P}<0.05$ was considered to indicate a statistically significant difference.

\section{Results}

Size and $\zeta$-potential of the nanoparticles. The average size and $\zeta$-potential of the mPEG-PEI-SPION and 
Table I. $\zeta$-potential and size of mPEG-PEI-SPION and PinX1-siRNA/mPEG-PEI-SPION (N/P=5).

\begin{tabular}{lrr}
\hline Nanoparticle & S-potential, mV & Size, nm \\
\hline mPEG-PEI-SPION & $34.42 \pm 0.78$ & $39.6 \pm 1.2$ \\
PinX1-siRNA/mPEG-PEI-SPION (N/P=5) & $25.27 \pm 1.75$ & $126.3 \pm 2.3$
\end{tabular}

mPEG, monomethoxy polyethylene glycol; PEI, polyethyleneimine; SPION, superparamagnetic iron oxide nanoparticle; siRNA, short interfering RNA; PinX1, PIN2-interacting protein 1.

A

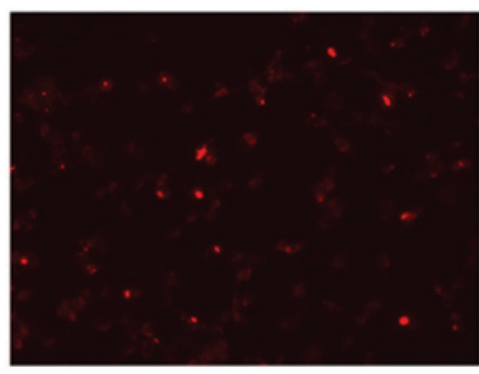

B

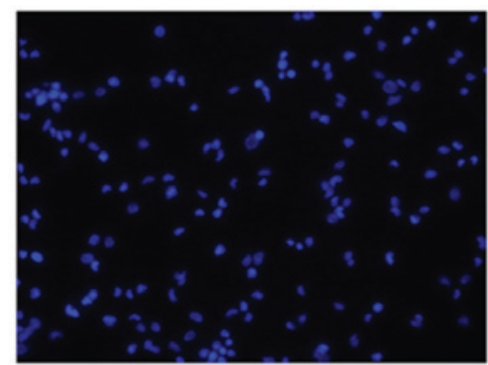

C

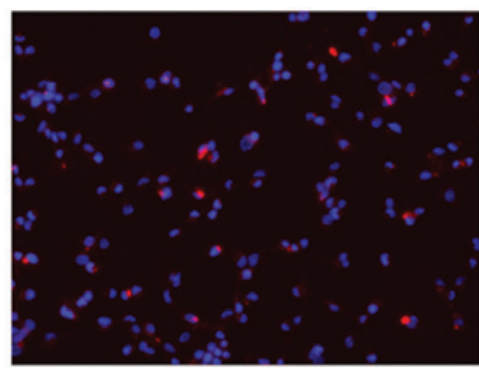

Figure 1. Fluorescent images of $\mathrm{C} 6$ cells after $4 \mathrm{~h}$ incubation with Cy3-siRNA/mPEG-PEI-SPION in (A) Cy3-contained cells, (B) Hoechst stained cells and (C) a merged image. As demonstrated in the images, Cy3 was detected in the cytoplasm of almost all the cells, indicating that Cy3-siRNA/mPEG-PEI-SPION was transfected with high efficiency. mPEG, monomethoxy polyethylene glycol; PEI, polyethyleneimine; SPION, superparamagnetic iron oxide nanoparticle; siRNA, short interfering RNA.

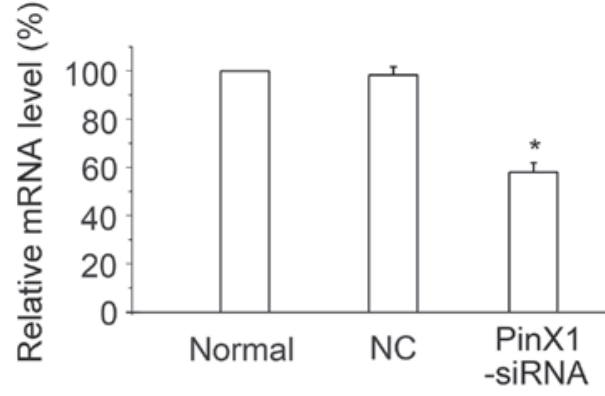

Figure 2. qPCR analysis of PinX1 mRNA expression levels revealed that NC-siRNA did not affect the PinX1 mRNA expression levels ( $P>0.05$, vs normal group). However, PinX1-siRNA did reduce the PinX1 mRNA expression levels to $57.7 \%$ of the NC group ( $\mathrm{P}<0.05$, vs. normal group). qPCR, quantitative polymerase chain reaction; PinX1, PIN2-interacting protein 1 siRNA, short interfering RNA; NC, negative control.

siRNA/mPEG-PEI-SPION complexes are shown in Table I. Sizes of PinX1-siRNA/mPEG-PEI-SPIONs ranged between 100 and $150 \mathrm{~nm}$, which was a suitable size for higher specific surface area and better penetrability. The average $\xi$-potential of PinX1-siRNA/mPEG-PEI-SPIONs was 25.27 $\pm 1.75 \mathrm{mV}$, which enabled the absorption of PinX1-siRNA/mPEG-PEI-SPIONs through the cell membrane which has a negative potential.

Transfection and knockdown. In the transfection of Cy3-siRNA/mPEG-PEI-SPION into C6 cells, Cy3-siRNA/mPEG-PEI-SPION was shown to be efficiently delivered into C6 cells. As shown in Fig. 1, almost all the C6 cells were transfected with Cy3-siRNA/mPEG-PEI-SPION. The following qPCR experiment demonstrated that PinX1-siRNA/mPEG-PEI-SPION transfection resulted in a knockdown of PinX1 mRNA expression (Fig. 2), while

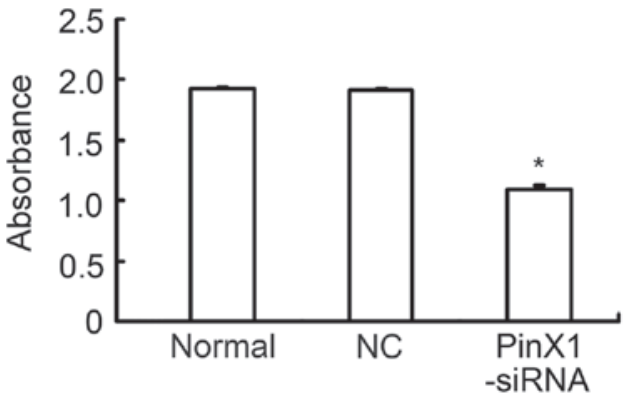

Figure 3. Absorbance values of each group using the telomerase PCR ELISA assay. There was no significant difference in the absorbance values between the NC-siRNA and normal groups. However, the PinX1-siRNA group exhibited a markedly decreased absorbance value as compared with the normal group. ${ }^{*} \mathrm{P}<0.05$, vs. normal group. $\mathrm{PCR}$, polymerase chain reaction; PinX1, PIN2-interacting protein 1; siRNA, short interfering RNA; NC, negative control.

NC-siRNA/mPEG-PEI-SPION did not have this effect. Therefore, mPEG-PEI-SPION is an ideal tool for delivering siRNA into C6 cells. Furthermore, transfection of $100 \mathrm{nM}$ PinX1-siRNA/mPEG-PEI-SPION significantly decreased telomerase activity in C6 cells (Fig. 3).

Cell viability. Administration of $10 \mu \mathrm{g} / \mathrm{ml}$ DOX resulted in a prominent decrease in cell viability when compared with the normal controls. PinX1-siRNA alone was unable to cause cytotoxicity in the observed time period, however, when used in combination with DOX, PinX1-siRNA was able to sensitize the inhibition effect of DOX. PinX1-siRNA decreased cell viability by $\sim 12.3 \%$, as measured by the CCK- 8 method (Fig. 4). In addition, PinX1-siRNA enhanced the cell toxicity of DOX by promoting cell death and apoptosis, as shown by Hoechst 33243 staining (Fig. 5). 


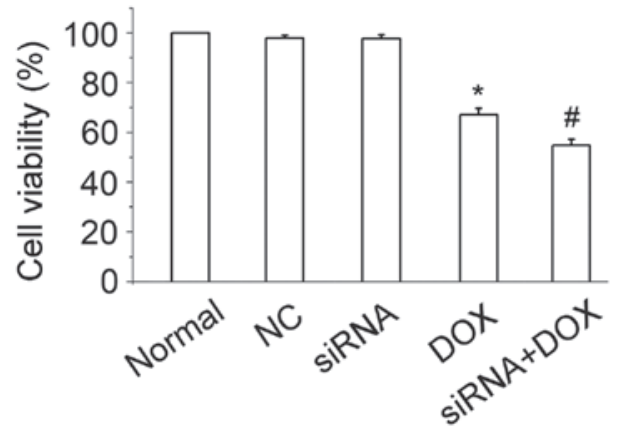

Figure 4. PinX1-siRNA increased the cell toxicity of DOX. Treatment with $10 \mu \mathrm{g} / \mathrm{ml}$ DOX reduced cell viability to $67 \%$ of the normal group. PinX1-siRNA alone did not decrease the cell viability. Cells treated with a combination of PinX1-siRNA and DOX exhibited a cell viability of 54.7\%, which was significantly lower when compared with the DOX group. " $\mathrm{P}<0.05$, vs. normal group; ${ }^{\#} \mathrm{P}<0.05$, vs. DOX group. DOX, doxorubicin; PinX1, PIN2-interacting protein 1; siRNA, short interfering RNA.

\section{Discussion}

The anthracycline chemical DOX is a common antitumor agent, however, the drug is limited by its toxicity to healthy organisms, of which acute or chronic heart failure is the most severe (28).

Although siRNA has been shown to be a promising therapy, the delivery system is one of the obstacles for siRNA application, particularly in the nervous system which is difficult to transfect. Viruses mediate transfection at a high efficiency, but are limited by their immunogenicity. Nanomedicine is a rapidly developing field, and due to the increasing interest, marked progress has been made in the medical applications of nanoscale devices. Nanoparticles have been applied in disease diagnosis, treatment and prevention. Among them, cationic polymers are the most common. PEG, a type of cationic polymer, has been increasingly studied and identified to have a high transfection efficiency, thus, currently PEG is considered to be the gold standard of transfection efficiency (29). Furthermore, PEG has been modified with PEI to obtain mPEG-PEI, an improved nanoparticle with less toxicity, more target activity and improved stability. In addition, mPEG-PEI can be labeled with other molecules to obtain various characteristics, including SPION, a magnetic nanoparticle which is detectable by MRI. Medarova et al (30) successfully used SPION-labeled nanoparticles to deliver siRNA to tumor cells. In the present study, mPEG-PEI-SPION was competent in forming complexes with siRNA and entering C6 cells, which facilitated further in vivo study with MRI. To the best of our knowledge, the current study is the first to apply this system in C6 cells.

Telomeres function as protective structures that cap the ends of chromosomes. They consist of terminal TTAGGG repeats and telomere-specific DNA binding proteins. With each cell division, the 5 ' end of the telomere is shortened by 50-200 nucleotides. Therefore, following several replications, the telomeres reach a threshold and cell proliferation arrest or cell death occurs. Telomerase is an RNA-dependent DNA polymerase that functions as a reverse transcriptase which is responsible for the synthesis of telomeres. Telomerase prevents the shortening of telomeres and is essential for the maintenance
A

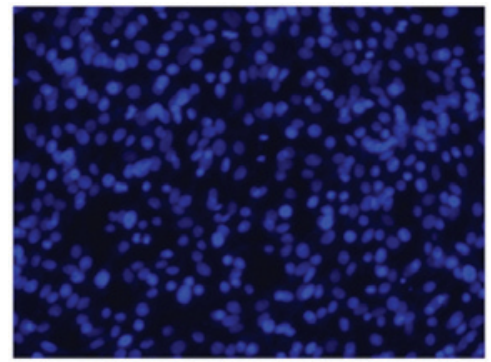

B

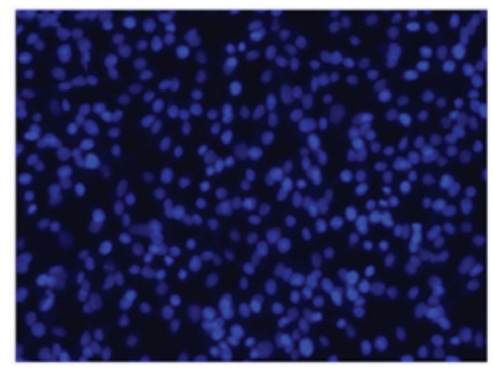

C

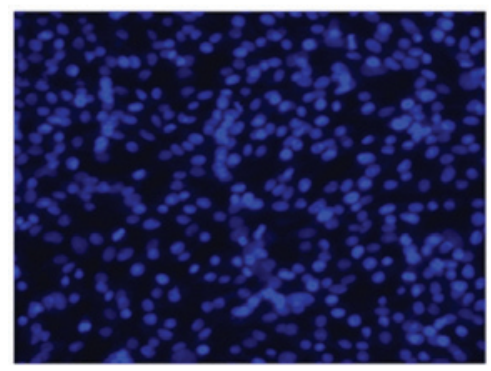

D

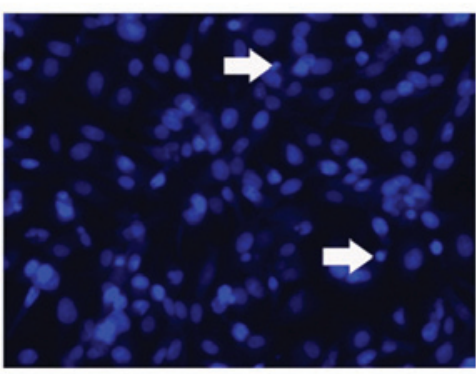

$\mathbf{E}$

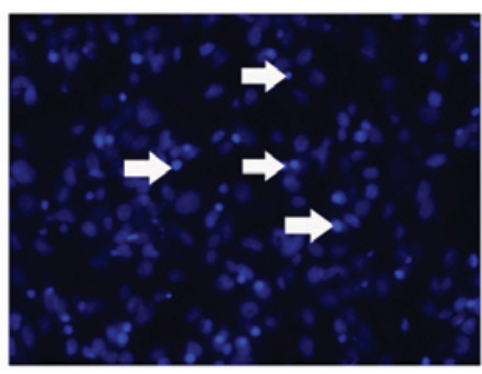

Figure 5. Hoechst staining images of $\mathrm{C} 6$ cells in the (A) normal control, (B) NC-siRNA control, (C) PinX1-siRNA, (D) DOX and (E) DOX + PinX1-siRNA groups. Representative images revealed that $10 \mu \mathrm{g} / \mathrm{ml}$ DOX caused decreased cell numbers and nucleus fragmentation (arrows). Furthermore, if C6 cells were administered with PinX1-siRNA and DOX simultaneously, cell loss and nuclear condensation (arrows) were markedly more severe. DOX, doxorubicin; PinX1, PIN2-interacting protein 1; siRNA, short interfering RNA; NC, negative control.

of telomere length and activity. The activation of telomerase is considered to be critical in cell immortalization (11) and increasing evidence indicates that telomere dysfunction is a common driver for the genomic instability that is present in cancer (31). Ding et al reactivated telomerase expression with the inducible mouse telomerase reverse transcriptase trans- 
gene in a prostate cancer mouse model. The authors found that re-expression of telomerase in the prostate epithelium generated more aggressive tumors (32). These results further indicate that telomerase may be a potent target for combating tumors.

PinX1 is a conserved nucleolar protein that has complex roles in telomerase/telomere regulation and cancer. In the study by Zhou and Lu, downregulation of PinX1 expression via antisense cDNA transfection resulted in increased telomerase activity, increased telomere length and enhanced tumor malignancy in the HT1080 (telomerase-positive) cancer cell line. These results indicated that PinX1 is a telomerase/telomere inhibitor and a putative tumor suppressor in humans (18). However, whether PinX1 is tumor-suppresive or promotive remains elusive. In the present study, transfection of PinX1-siRNA/mPEG-PEI-SPION into C6 cells not only resulted in the significant downregulation of PinX1 mRNA expression, but transfection also weakened telomerase activity. These observations support the hypothesis that PinX1 may be a target for suppressing tumor growth, in accordance with the study by Zhang et al (20).

The aims of the present study were to determine whether mPEG-PEI-SPION may be a device for siRNA delivery into $\mathrm{C} 6$ cells and whether the specific silencing of PinX1 by siRNA may improve the cytotoxic effect of DOX in C6 glioma cells. As demonstrated, a combination of PinX1-siRNA/mPEG-PEI-SPION and DOX resulted in increased cell loss when compared with DOX administration alone. Therefore, PinX1-siRNA/DOX is more efficient for inhibiting C6 growth. The results of the present study support the hypothesis that combined therapy with PinX1-siRNA/DOX can successfully maintain the tumor inhibition effect with reduced side effects.

In conclusion, the current study has demonstrated that mPEG-PEI-SPION is viable in delivering siRNA to C6 cells for the purpose of treatment. Furthermore, PinX1 may regulate telomerase activity and is therefore a potential target for inhibiting tumors. To the best of our knowledge, this is the first study to treat gliomas with a combination of DOX and PinX1-siRNA. In addition, since SPIONs can be monitored by MRI, the present study may be used as a pilot study for further investigation into the application of siRNA/mPEG-PEI-SPION for brain tumors in vivo.

\section{Acknowledgements}

The study was supported by grants from the National Natural Science Foundation of China (nos. 30672411, 30973479 and 81301088), the '863' Programs of China (no. 2007AA021101) and the Science and Technology Planning Project of Guangdong Province, China (nos. 2009B060700040 and 2011B031800141).

\section{References}

1. Sengupta S, Marrinan J, Frishman C and Sampath P: Impact of temozolomide on immune response during malignant glioma chemotherapy. Clin Dev Immunol 2012: 831090, 2012.

2. Shinojima N, Tada K, Shiraishi S, Kamiryo T, Kochi M, Nakamura H, Makino K, Saya H, Hirano H, Kuratsu J, Oka K, Ishimaru Y and Ushio Y: Prognostic value of epidermal growth factor receptor in patients with glioblastoma multiforme. Cancer Res 63: 6962-6970, 2003.
3. Jagannathan J, Prevedello DM, Dumont AS and Laws ER: Cellular signaling molecules as therapeutic targets in glioblastoma multiforme. Neurosurg Focus 20: E8, 2006.

4. De Ridder L: Behaviour of gliomas in vitro vs histopathological grading. Int J Dev Neurosci 17: 541-546, 1999.

5. Doroshow JH: Anthracycline antibiotic-stimulated superoxide, hydrogen peroxide, and hydroxyl radical production by NADH dehydrogenase. Cancer Res 43: 4543-4551, 1983.

6. Tewey KM, Rowe TC, Yang L, Halligan BD and Liu LF: Adriamycin-induced DNA damage mediated by mammalian DNA topoisomerase II. Science 226: 466-468, 1984.

7. Mukhopadhyay P, Rajesh M, Bátkai S, Kashiwaya Y, Haskó G, Liaudet L, Szabó C and Pacher P: Role of superoxide, nitric oxide, and peroxynitrite in doxorubicin-induced cell death in vivo and in vitro. Am J Physiol Heart Circ Physiol 296: H1466-H1483, 2009.

8. Rafiyath SM, Rasul M, Lee B, Wei G, Lamba G and Liu D: Comparison of safety and toxicity of liposomal doxorubicin vs. conventional anthracyclines: a meta-analysis. Exp Hematol Oncol 1: 10, 2012.

9. Carneiro T, Khair L, Reis CC, Borges V, Moser BA,Nakamura TM and Ferreira MG: Telomeres avoid end detection by severing the checkpoint signal transduction pathway. Nature 467: 228-232, 2010.

10. de Lange T: How telomeres solve the end-protection problem. Science 326: 948-952, 2009.

11. Shay JW and Bacchetti S: A survey of telomerase activity in human cancer. Eur J Cancer 33: 787-791, 1997.

12. Falchetti ML, Fiorenzo P, Mongiardi MP, Petrucci G, Montano N, Maira G, Pierconti F, Larocca LM, Levi A and Pallini R: Telomerase inhibition impairs tumor growth in glioblastoma xenografts. Neurol Res 28: 532-537, 2006.

13. Harada K, Kurisu K, Tahara H, Tahara E, Ide T and Tahara E: Telomerase activity in primary and secondary glioblastomas multiforme as a novel molecular tumor marker. J Neurosurg 93: 618-625, 2000.

14. Lai XF, Shen CX, Wen Z, Qian YH, Yu CS, Wang JQ, Zhong PN and Wang HL: PinX1 regulation of telomerase activity and apoptosis in nasopharyngeal carcinoma cells. J Exp Clin Cancer Res 31: 12, 2012

15. Chang Q, Pang JC, Li J, Hu L, Kong X and Ng HK: Molecular analysis of PinX1 in medulloblastomas. Int J Cancer 109: 309-314, 2004

16. Hawkins GA, Chang BL, Zheng SL, Isaacs SD, Wiley KE, Bleecker ER, Walsh PC, Meyers DA, Xu J and Isaacs WB: Mutational analysis of PINX1 in hereditary prostate cancer. Prostate 60: 298-302, 2004.

17. Oh BK, Chae KJ, Park C and Park YN: Molecular analysis of PinX1 in human hepatocellular carcinoma. Oncol Rep 12: 861-866, 2004.

18. Zhou XZ and Lu KP: The PIN2/TRF1-interacting protein PINX1 is a potent telomerase inhibitor. Cell 107: 347-359, 2001.

19. Guglielmi B and Werner M: The yeast homolog of human PinX1 is involved in rRNA and small nucleolar RNA maturation, not in telomere elongation inhibition. J Biol Chem 277: 35712-35719, 2002.

20. Zhang B, Bai YX, Ma HH, Feng F, Jin R, Wang ZL, Lin J, Sun SP, Yang P, Wang XX, Huang PT, Huang CF, Peng Y, Chen YC, Kung HF and Huang JJ: Silencing PinX1 compromises telomere length maintenance as well as tumorigenicity in telomerase-positive human cancer cells. Cancer Res 69: 75-83, 2009.

21. Jackson AL, Bartz SR, Schelter J, Kobayashi SV, Burchard J, Mao M, Li B, Cavet G and Linsley PS: Expression profiling reveals off-target gene regulation by RNAi. Nat Biotechnol 21: 635-637, 2003

22. Malek A, Merkel O, Fink L, Czubayko F, Kissel T and Aigner A: In vivo pharmacokinetics, tissue distribution and underlying mechanisms of various PEI(-PEG)/siRNA complexes. Toxicol Appl Pharmacol 236: 97-108, 2009.

23. Moghimi SM, Hunter AC and Murray JC: Nanomedicine: current status and future prospects. FASEB J 19: 311-330, 2005.

24. Alwi R, Telenkov S, Mandelis A, Leshuk T, Gu F, Oladepo S and Michaelian K: Silica-coated super paramagnetic iron oxide nanoparticles (SPION) as biocompatible contrast agent in biomedical photoacoustics. Biomed Opt Express 3: 2500-2509, 2012.

25. Sun S, Zeng H, Robinson DB, Raoux S, Rice PM, Wang SX and Li G: Monodisperse $\mathrm{MFe}_{2} \mathrm{O}_{4}(\mathrm{M}=\mathrm{Fe}, \mathrm{Co}, \mathrm{Mn})$ nanoparticles. J Am Chem Soc 126: 273-279, 2004. 
26. Chen G, Chen W, Wu Z, Yuan R, Li H, Gao J and Shuai X: MRI-visible polymeric vector bearing CD3 single chain antibody for gene delivery to $\mathrm{T}$ cells for immunosuppression. Biomaterials 30: 1962-1970, 2009.

27. Tromsdorf UI, Bigall NC, Kaul MG, Bruns OT, Nikolic MS, Mollwitz B, Sperling RA, Reimer R, Hohenberg H, Parak WJ, Förster S, Beisiegel U, Adam G and Weller H: Size and surface effects on the MRI relaxivity of manganese ferrite nanoparticle contrast agents. Nano Lett 7: 2422-2427, 2007.

28. Ito H, Miller SC, Billingham ME, Akimoto H, Torti SV, Wade R, Gahlmann R, Lyons G, Kedes L and Torti FM: Doxorubicin selectively inhibits muscle gene expression in cardiac muscle cells in vivo and in vitro. Proc Natl Acad Sci USA 87: 4275-4279, 1990.
29. Zwiorek K, Kloeckner J, Wagner E and Coester C: Gelatin nanoparticles as a new and simple gene delivery system. J Pharm Pharm Sci 7: 22-28, 2005

30. Medarova Z, Pham W, Farrar C, Petkova V and Moore A: In vivo imaging of siRNA delivery and silencing in tumors. Nat Med 13: 372-377, 2007.

31. Murnane JP: Telomere dysfunction and chromosome instability. Mutat Res 730: 28-36, 2012.

32. Ding Z, Wu CJ, Jaskelioff M, Ivanova E, Kost-Alimova M, Protopopov A, Chu GC, Wang G, Lu X, Labrot ES, Hu J, Wang W, Xiao Y, Zhang H, Zhang J, Zhang J, Gan B, Perry SR, Jiang S, Li L, Horner JW, Wang YA, Chin L and DePinho RA: Telomerase reactivation following telomere dysfunction yields murine prostate tumors with bone metastases. Cell 148: 896-907, 2012. 